\title{
Analysis of utility and use of a web-based tool for digital signal processing teaching by means of a technological acceptance model
}

\author{
S.L. Toral *, F. Barrero, M.R. Martínez-Torres \\ Department of Electronic Engineering, University of Seville, Avda. Camino de los, Descubrimientos s/n, \\ Seville 41092, Spain
}

\begin{abstract}
This paper presents an exploratory study about the development of a structural and measurement model for the technological acceptance (TAM) of a web-based educational tool. The aim consists of measuring not only the use of this tool, but also the external variables with a significant influence in its use for planning future improvements. The tool, designed with Shockwave ${ }^{\mathrm{TM}}$ and Macromedia Director ${ }^{\mathrm{TM}}$, is a web-based educational environment that has been applied as a teaching methodology in an undergraduate course involved with modern microprocessors architectures and applications. The proposed methodology may be extensible to similar tools and tries to fill the lack of scientific studies in the validation and acceptance of computer-based educational tools.

(C) 2005 Elsevier Ltd. All rights reserved.
\end{abstract}

Keywords: Information systems theory; Technological acceptance model; Distributed learning environments; Interactive learning environments; Multimedia/hypermedia systems

\footnotetext{
* Corresponding author. Tel.: +34954 4812 93; fax: +34 954487373 .

E-mail address: toral@esi.us.es (S.L. Toral).
} 


\section{Introduction}

In recent years there have been important changes in engineering education, especially in electrical and computer engineering (ECE) education, both in terms of content (curriculum) and what it is taught or how it is taught (delivery of material) (Carley, Khosla, \& Unetich, 2000; Felder, Felder, \& Dietz, 1998; Milliken \& Barnes, 2002; Roppel, 2000; Taylor, Heer, \& Fiez, 2003; Wilson \& Jennings, 2000).

On the one hand, emphasis in the electrical engineering field has shifted significantly to the design of digital systems. On the other hand, technology that is around everything we do, has taken a place in the classroom. Since the early days of computers, learning through computer-based environments (hypermedia tools, web-based educational support, simulation environments, etc.) has dramatically increased (Aedo, Díaz, Fernández, Martín, \& Berlanga, 2000; Almeida, Piazzalunga, Ribeiro, Casemiro, \& Moreno, 2003; Bagui, 1998; Christian \& Belloni, 2001; Conole, Dyke, Oliver, \& Seale, 2004; Metzger, Flanagina, \& Zwarun, 2003; Pahl, 2003).

The pedagogical value of computer and web-based educational tools has been demonstrated in a lot of situations and educational experiences. But, although many enhancements have been developed in this area over the years, not much attention has been paid to scientific analysis for validating the tools in order to improve the teaching process; once a computer-based educational tool has been designed, it is never validated or, at most, poorly validated. However, two kinds of approaches to the task of e-learning or web-based educational tools evaluation can be distinguished.

The first one is based on a simple questionnaire followed by a basic statistical treatment. The majority of the provided assessment data in scientific studies correspond to this scheme. Sometimes, just cognitive outcomes are considered (Fuller \& Moreno, 2004). Other times, several dimensions about user perceptions are included. In Abdel-Qader, Bazuin, Mousavinezhad, and Patrick (2003), overall satisfaction and quality of materials are the unique variables taken into account. More elaborated questionnaires considering new dimensions can be found in Chevalier, Craddock, Riley, and Trunk (2000), Avouris, Tselios, and Tatakis (2001) and Hurley and Lee (2005). But in all the cases, the data treatment is reduced to show frequency of user answers.

The second kind of approaches consists of a more complex questionnaire followed by a more complex statistical study, usually a multivariate statistical analysis. There is a big difference respect to the previous approach: the focus of attention is not only the use, satisfaction or efficiency of the tool, but the variables with an incidence over this final result and how these variables are interrelated among them. Some attempts in this field are worth mentioning. In Cappel and Hayen (2004), a questionnaire is used to test the satisfaction, perceived effectiveness and quality of an e-learning tool. But this questionnaire includes also questions related to some specific learning dimensions, such as clarity of information, easy of use, usefulness, etc. Several dimensions are also used in Toral, Barrero, Martínez-Torres, Gallardo, and Lillo (2005), although in this case a correlation analysis is performed to extract some conclusions about relationships among dimensions. Some other studies are based on a previous model taken from information systems theory: the technological acceptance model (TAM). Basically, TAM models how users use a technology. In Selim (2003), Ngai, Poon, and Chan (2007) Ong, Lai, and Wang (2004) TAM is applied to a web-based and to an asynchronous e-learning tool. In the first case, the original model has been used while in the next two cases an external dimension has been added. 
Following this trend, this paper proposes the application of the technological acceptance model (TAM) to validate the application of a web-based educational tool as a teaching methodology and to plan future improvements. The tool has been used in an advanced microprocessor technology course, included in the telecommunication engineering curriculum at the University of Seville (Spain), since academic year 2002-2003. As a difference to the previous studies based on TAM, this study considers the most frequently mentioned external variables in the literature as external dimensions with an incidence over TAM variables. A methodology to achieve the complete model to be applied is also detailed.

The paper is organized as follows. First, the web-based educational tool and the course are introduced. Then, the methodology used to validate the utility and use of the educational tool is described. The first step of this methodology consists of validating a questionnaire using Cronbach's alpha. Through this index, the main constructs or dimensions related to the TAM model are validated and a set of indicators are obtained. Due to the large number of dimensions and indicators, a principal component analysis (PCA) technique is then applied to reduce the number of variables. The principal component of each dimension is used to obtain both a small number of indicators and to measure all the correlations among the different detected dimensions. Using the results of PCA analysis as a starting point, a structural equation model technique (PLS, partial least square) is then applied to obtain the final structural and measurement TAM model. The correlations of PCA analysis are used as the hypothesis to be validated and the weigh of indicators in the first principal component is used to obtain the minimum number of indicators to be used in PLS analysis. The results allow both measuring the use of the tool and determining the external variables with a significant influence in this use. Future improvements and conclusions will be pointed out in the final section.

\section{Web-based educational tool to improve DSP teaching for undergraduate}

Telecommunication engineering studies at the University of Seville, was first organized in 1991. An intermediate undergraduate digital electronic subject-based on the design of advanced embedded digital systems and DSPs has been taught since then. The lack of enough lab work in the original organization of studies motivated a change in 1998, searching for an increment in the practical work. This fact, together with the necessity of improving the teaching methodology in classrooms with more than 300 students per year, was the starting point to develop new teaching methods using computer-based educational tools. In this approach, it has also been taken into account the new European Area for Higher Education and ECTS credits, which will shortly modify the teaching and learning processes (Communiqué of the Conference of Ministers responsible for Higher Education, 2003; Joint declaration of the European Ministers of Education, 1999).

The course has been used to teach advanced microprocessors architecture connecting hardware concepts with software and, even, theoretical knowledge related to digital signal processing. We have chosen a DSP, Texas Instruments C3x family, as an example of microprocessor architecture to fully accomplish the objectives of the course; the internal structure of $\mathrm{C} 3 \mathrm{x}$ family is used to explain complex embedded systems and its utility in telecommunication area. The TMS320C3X family is a 32 bits floating point general-purpose DSP from Texas Instruments (TI ${ }^{\mathrm{TM}}$, http:// www.ti.com). The family architecture features present a central processing module that appears 
in all family members and it has been designed to execute commonly-used digital signal processing benchmarks with a minimum time load for single-multiplier architecture. These DSPs optimize speed implementing functions in hardware whereas other processors implement them through software or microcodes, performing parallel multiply and ALU operations on integer or floating-point data in a single cycle. Each processor also possesses a general-purpose register file, a program cache, dedicated ARAUs, internal dual-access memories, one DMA channel supporting concurrent I/O, and a short machine-cycle time. General-purpose applications are greatly enhanced by the large addresses space, multiprocessor interface, internally and externally generated wait states, two external interface ports, two timers, serial ports, and multiple interrupt structure.

The analyzed educational tool consists of a web-site that has been designed (http:// www.gte.us.es/ fbarrero/CSED/) to promote an asynchronous learning forum, a group work environment for collaborative learning and a multimedia learning tool. This tool has been developed taking into account traditional elements of the TAM models: usefulness and easy of use. We have designed this site to be used in different teaching scenarios (lab exercises, theoretical lessons, self-learning, etc.). Students can access teaching material using this tool, to chat and discuss about the concepts of the course and to download data files containing reference material and class notes in pdf format. Other capabilities, based on data bases programmed using PHP, Perl Hypertext Preprocessor, are provided (see Figs. 1-4); student auto-evaluation tool, doubt, notice and mark boards, quality inquiry to provide asynchronous feedback of the teaching process, chat service. Maintenance of the web site is easily done with administration protected pages programmed using PHP.

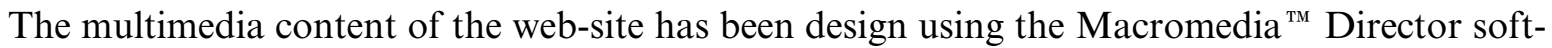
ware (Figs. 5-10), and it can be used in traditional classrooms and for asynchronous and noneyewitness active self-learning to engage students in active reinforcement of the concepts acquired in class. Notice that Director allows the development of dynamic web pages due to Shockwave

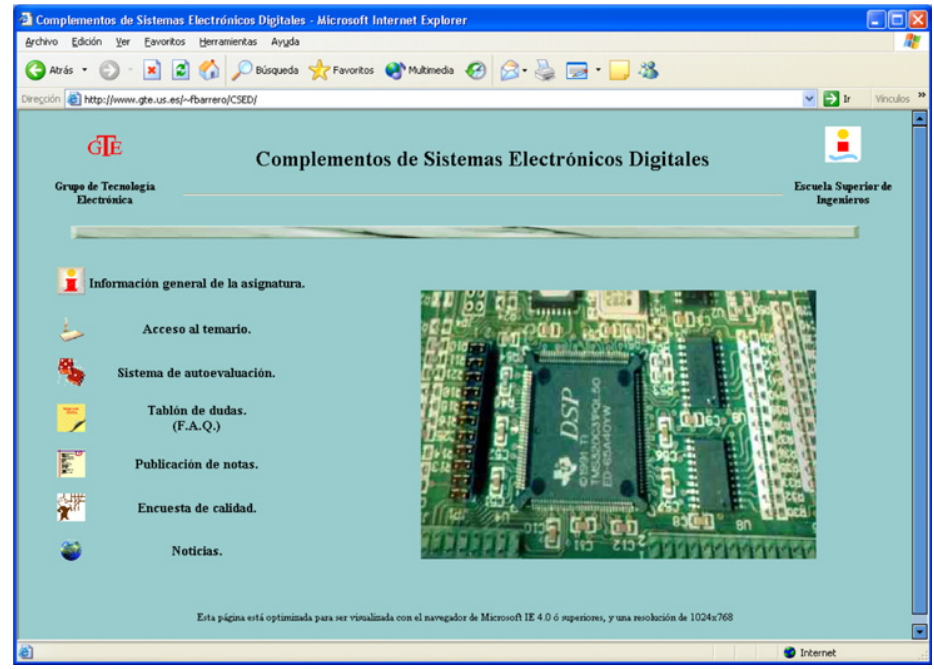

Fig. 1. Learning forum welcome screen. 


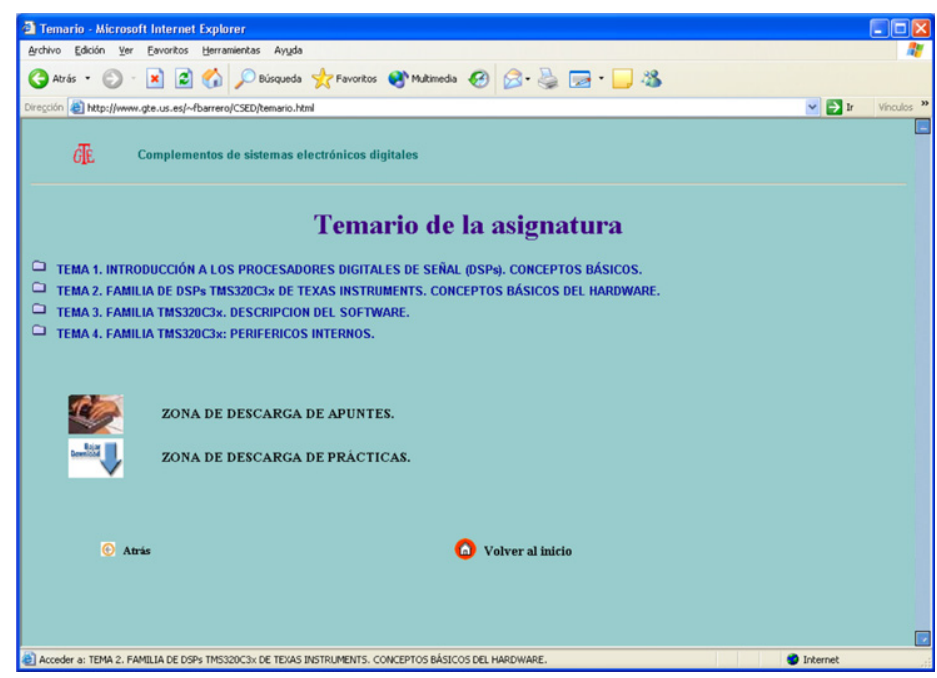

Fig. 2. Teaching material access (I): download and on-line access.

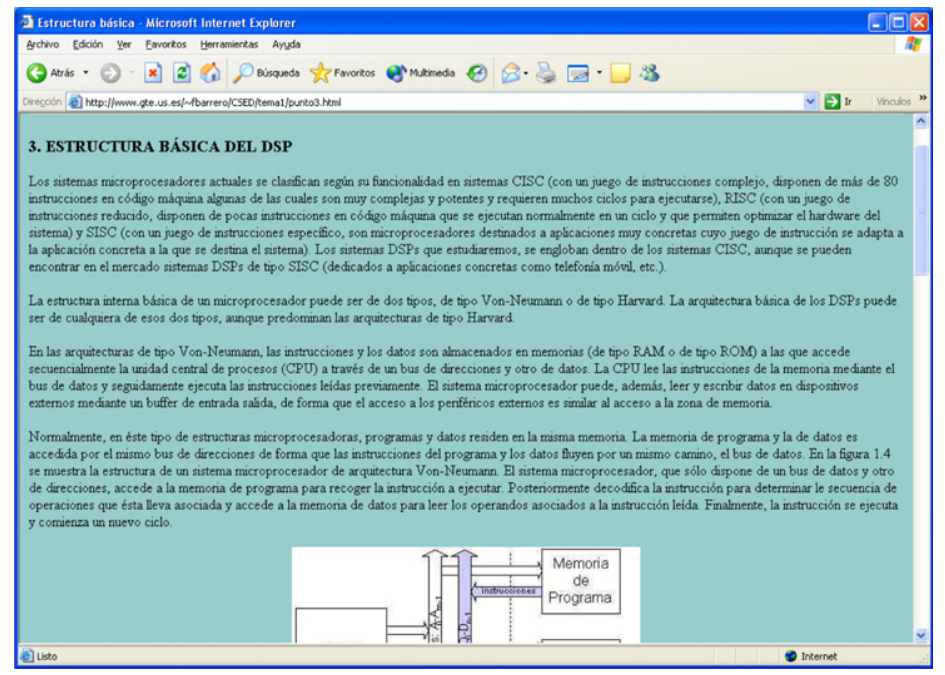

Fig. 3. Teaching material access (II): on-line access.

compression techniques and that a Shockwave site needs a browser with a Shockwave Player plug-in (this plug-in is self-detected and it is free-downloadable in case of necessity).

The multimedia content is a tight coupling of text, tutorials, illustrations, video segments and animations that integrates theoretic concepts related to TMS320C3X internal architecture and practical experiences to guarantee a "learning by doing" philosophy. In fact, two learning units have been designed, one devoted to the theoretical teaching and the other one related to practical exercises and lab work carried out during the academic year. After a small visual introduction, each unit can be accessed. 


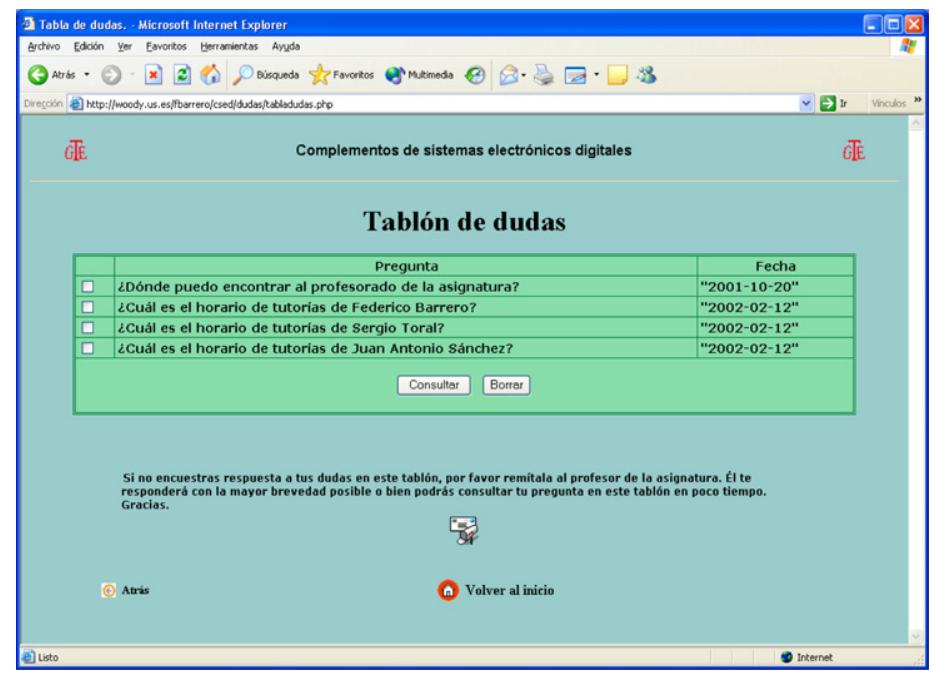

Fig. 4. Doubt board.

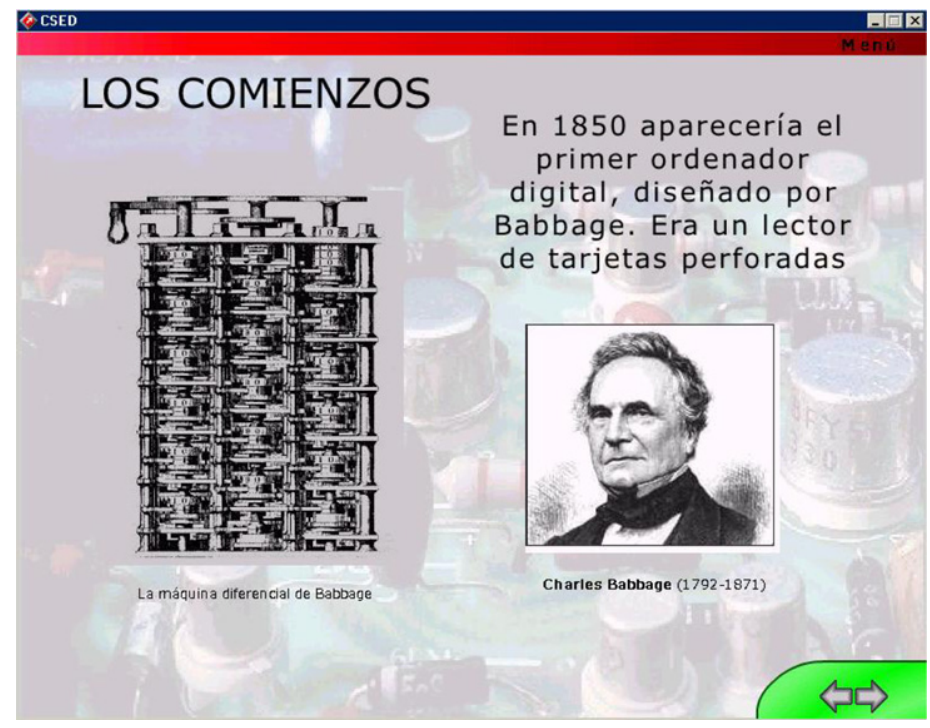

Fig. 5. Embedded systems: the beginnings.

On the one hand, the theoretical unit consists of four sections, plus a generic embedded systems introduction. These chapters consist of:

- An introduction to the DSP devices concepts and their main applications.

- Basic hardware concepts of TMS320C3X devices: CPU and internal bus operations, memory organization and external bus timing access. 


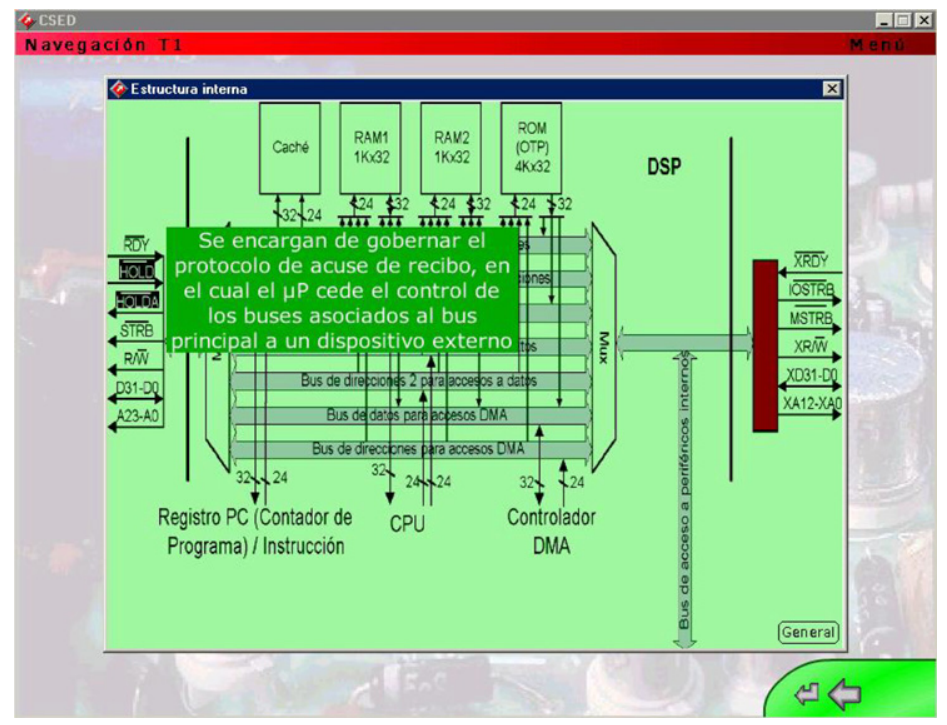

Fig. 6. TMS320C3X internal architecture description.

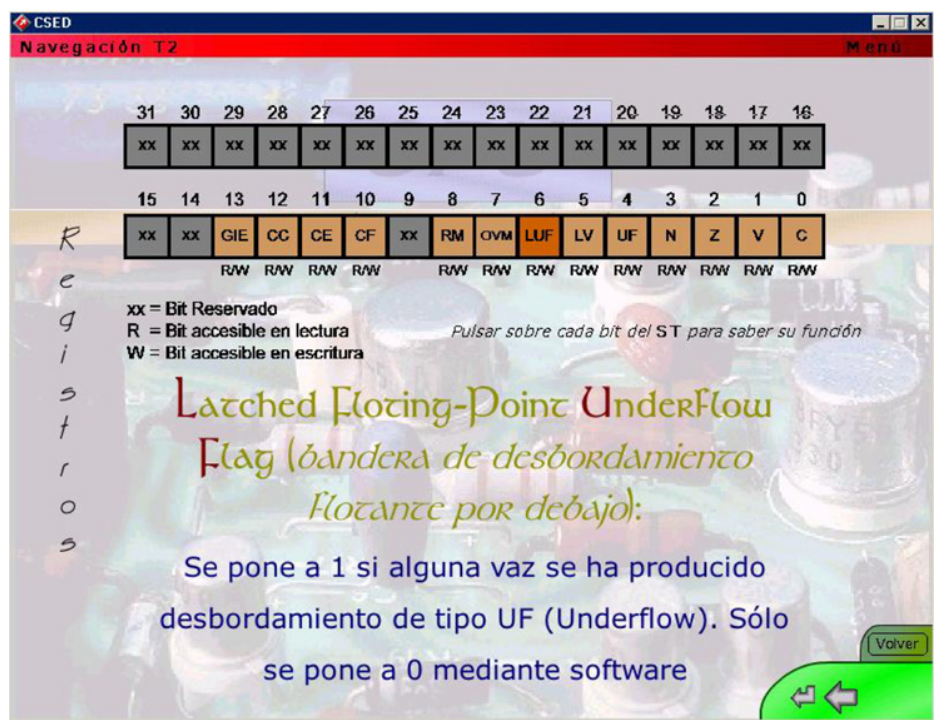

Fig. 7. TMS320C3X status register.

- Basic software concepts of TMS320C3X devices: data format, addressing modes and basic assembler instructions.

- Internal peripheral: timers, serial interfaces and DMA.

On the other hand, the practical unit is based on nine chapters that include the necessary didactic material for the implementation of four lab exercises using a DSP starter kit (DSK30 platform). The content of this unit is organized in the following way: 


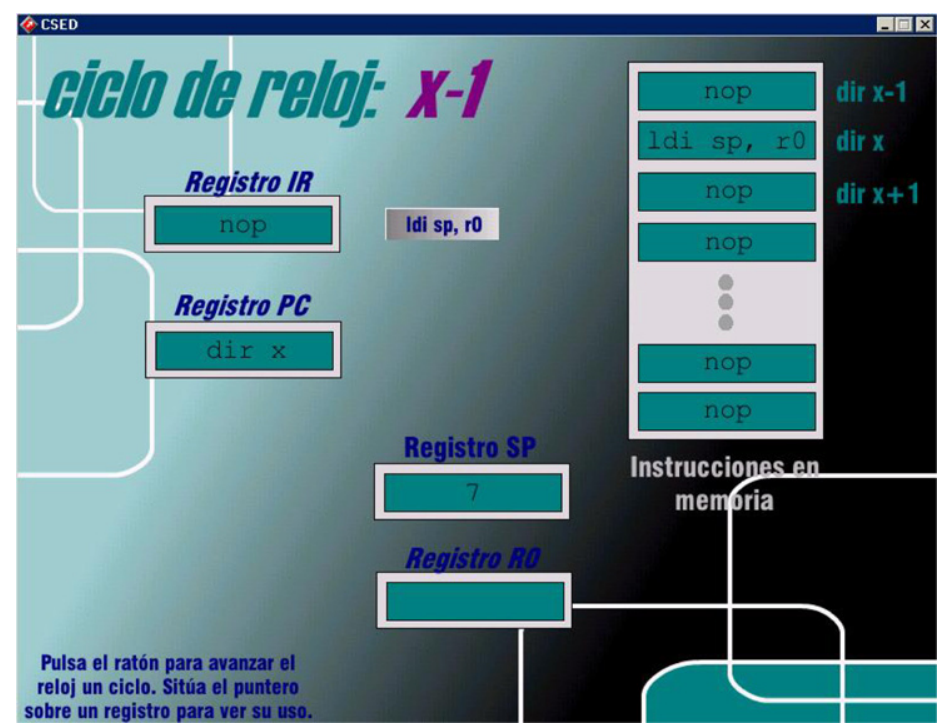

Fig. 8. Register addressing mode.

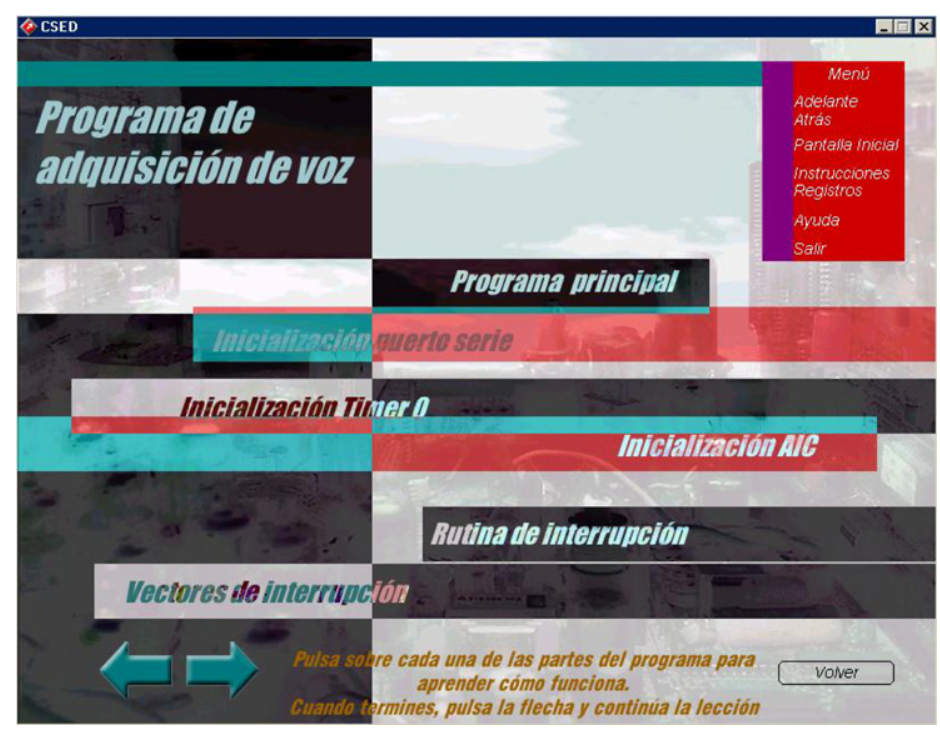

Fig. 9. Lab exercise based on audio signal processing.

- Different DSP applications are presented; implementation of audio signal processing techniques, digital wave generators and FIR or IIR filters.

- Some tutorials have been included; assembler instructions and addressing modes, description of program architecture, DSK30 functionality and characteristics.

- Moreover, two databases have been included to allow easy access to CPU instruction and internal DSP registers description, and a student auto-evaluation tool. 


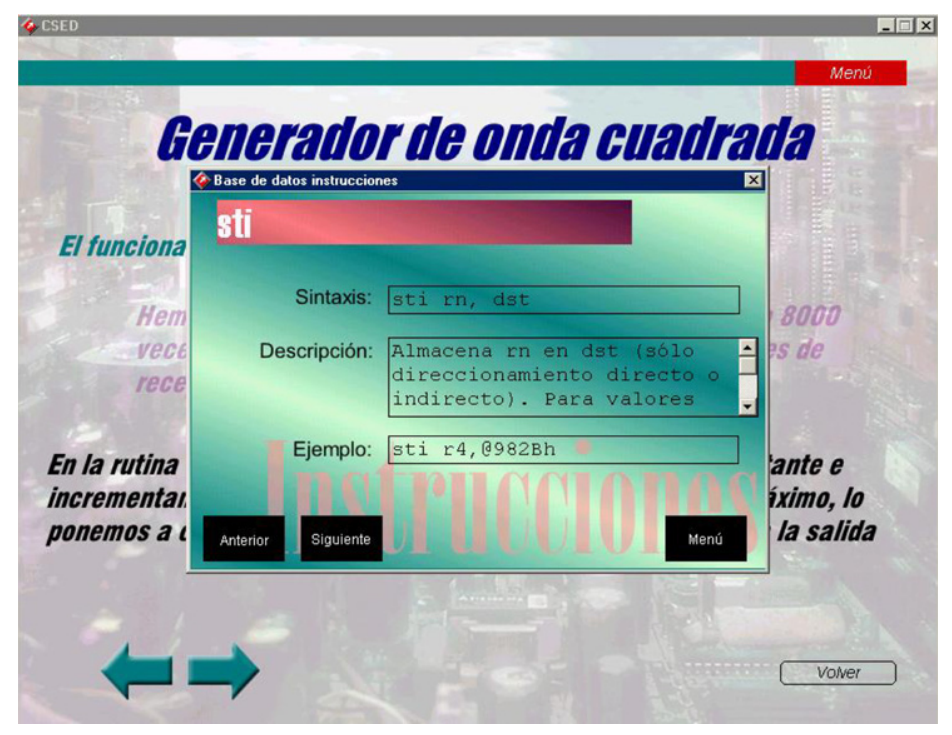

Fig. 10. One of the included databases: instruction database.

\section{Questionnaire validation}

To validate the tool previously described, a questionnaire has been prepared to achieve the following aims:

- Checking the use of the tool.

- Identifying the external variables with a sensible influence in the use of the tool.

The questionnaire, distributed among 142 students of the course, consists of 62 questions using 1-7 Likert type scale (1, strongly disagree; 7, strongly agree). Table 1 summarizes the technical chart of the study carried out. The questionnaire (detailed in Table 2) has groups of questions to measure several dimensions frequently reported in the literature: learning goal orientation, application specific self-efficacy and enjoyment (Agarwal \& Karahanna, 2000; Yi \& Hwang, 2003), focused immersion, curiosity, playfulness and voluntariness (Agarwal \& Karahanna,

Table 1

Technical chart of the study

\begin{tabular}{ll}
\hline Universe & Students with personal experience with the tool \\
Information gathering method & Personal survey \\
Sample unit & Students who has attended the DSP course \\
Population census & 155 \\
Sample size & 142 \\
Sample error & $3.15 \%$ \\
Reliability level & $99 \%, Z=2.58, p=q=0.5$ \\
Sample procedure & The survey was directed to the totally of the student attending the DSP course \\
Date of the field study & The survey was carried out in May, 2004 \\
\hline
\end{tabular}


Table 2

Validation of a questionnaire using Cronbach's alpha

\begin{tabular}{|c|c|c|}
\hline Dimension (reliability) & & Item (correlation item-dimension) \\
\hline \multirow[t]{7}{*}{$\begin{array}{l}\text { Learning goal } \\
\text { orientation }(0.8000)\end{array}$} & 1 & $\begin{array}{l}\text { I am willing to select a challenging work assignment that I can learn from } \\
(0.3580)\end{array}$ \\
\hline & 2 & I often look for opportunities to develop new skills and knowledge (0.5779) \\
\hline & 3 & I enjoy challenging and difficult tasks where I will learn new skills $(0.6614)$ \\
\hline & 4 & For me, developing my work ability is important enough to take risks $(0.5495)$ \\
\hline & 5 & $\begin{array}{l}\text { I prefer to work in situations that require a high level of ability and talent } \\
(0.5801)\end{array}$ \\
\hline & 6 & I like to experiment with new information technologies $(0.6191)$ \\
\hline & 7 & $\begin{array}{l}\text { Among my peers, I am usually the first to try out new information technologies } \\
(0.3606)\end{array}$ \\
\hline \multirow{15}{*}{$\begin{array}{l}\text { Application specific } \\
\text { self-efficacy }(0.8390)\end{array}$} & 1 & I have the ability of accessing web-based tool contents $(0.3761)$ \\
\hline & 2 & $\begin{array}{l}\text { I have the ability of navigating through the web-based tool contents in a defined } \\
\text { way }(0.5994)\end{array}$ \\
\hline & 3 & $\begin{array}{l}\text { I have the ability of navigating through the web-based tool contents following my } \\
\text { own way }(0.4253)\end{array}$ \\
\hline & 4 & $\begin{array}{l}\text { I can easily navigate from the theoretical part to the practical part and vice versa } \\
(0.4843)\end{array}$ \\
\hline & 5 & $\begin{array}{l}\text { I have the ability of developing code for the DSP working with the web-based tool } \\
(0.4164)\end{array}$ \\
\hline & 6 & $\begin{array}{l}\text { I understand better the practical part of the exam thanks to the web-based tool } \\
(0.3690)\end{array}$ \\
\hline & 7 & $\begin{array}{l}\text { I understand better the addressing modes of the DSP thanks to the web-based tool } \\
(0.4227)\end{array}$ \\
\hline & 8 & $\begin{array}{l}\text { I can easily program internal peripherals of the DSP using the web-based tool } \\
(0.4780)\end{array}$ \\
\hline & 9 & I have the ability of accessing the DSP instruction set database $(0.5995)$ \\
\hline & 10 & I have the ability of accessing the DSP internal register database $(0.6513)$ \\
\hline & 11 & $\begin{array}{l}\text { I have the ability of working with the web-based tool without previously using a } \\
\text { similar package }(0.4284)\end{array}$ \\
\hline & 12 & $\begin{array}{l}\text { I have the ability of working with the web-based tool without a detailed } \\
\text { explanation about it }(0.4466)\end{array}$ \\
\hline & 13 & $\begin{array}{l}\text { I can only work with the web-based tool if I have previously seen someone } \\
\text { working with it }(0.3933)\end{array}$ \\
\hline & 14 & $\begin{array}{l}\text { I can only work with the web-based tool if I have a user guide or software } \\
\text { manuals }(0.3150)\end{array}$ \\
\hline & 15 & I can only work with the web-based tool if I have enough time $(0.5003)$ \\
\hline \multirow[t]{3}{*}{ Enjoyment (0.8389) } & 1 & I have fun using the web-based tool $(0.5340)$ \\
\hline & 2 & Using the web-based tool is pleasant $(0.5408)$ \\
\hline & 3 & I find using the web-based tool to be enjoyable $(0.5357)$ \\
\hline \multirow[t]{4}{*}{$\begin{array}{l}\text { Focused immersion } \\
\quad(0.7369)\end{array}$} & 1 & $\begin{array}{l}\text { While using the web-based tool I am able to block most } \\
\text { other distractions }(0.6548)\end{array}$ \\
\hline & 2 & While using the web-based tool, I am absorbed in what I am doing (0.8037) \\
\hline & 3 & $\begin{array}{l}\text { While on the web-based tool, I am immersed in the task } \\
\text { I am performing }(0.7703)\end{array}$ \\
\hline & 4 & $\begin{array}{l}\text { While on the web-based tool, my attention does not get } \\
\text { diverted very easily }(0.5626)\end{array}$ \\
\hline
\end{tabular}


Table 2 (continued)

\begin{tabular}{|c|c|c|}
\hline Dimension (reliability) & & Item (correlation item-dimension) \\
\hline \multirow{3}{*}{ Curiosity (0.7756) } & 1 & Using the web-based tool excites my curiosity $(0.5344)$ \\
\hline & 2 & Interacting with the web-based tool makes me curious $(0.7563)$ \\
\hline & 3 & Using the web-based tool arouses my imagination $(0.5579)$ \\
\hline \multirow{6}{*}{ Playfulness (0.9682) } & 1 & When using the web-based tool I am imaginative (0.8992) \\
\hline & 2 & When using the web-based tool I am spontaneous $(0.8889)$ \\
\hline & 3 & When using the web-based tool I am flexible (0.8738) \\
\hline & 4 & When using the web-based tool I am creative $(0.9058)$ \\
\hline & 5 & When using the web-based tool I am original $(0.8935)$ \\
\hline & 6 & When using the web-based tool I am inventive $(0.9173)$ \\
\hline \multirow[t]{3}{*}{ Voluntariness $(0.8157)$} & 1 & The use of the web-based tool is voluntary $(0.6250)$ \\
\hline & 2 & $\begin{array}{l}\text { Although it may be interesting, the use of the web-based tool } \\
\text { is optional }(0.7058)\end{array}$ \\
\hline & 3 & Lecturers does not require me to use the web-based tool (0.6729) \\
\hline \multirow[t]{6}{*}{ Easy of use $(0.9075)$} & 1 & Learning to use the web-based tool is easy for me $(0.5892)$ \\
\hline & 2 & I find it easy to get the web-based tool to do what I want it to do $(0.7220)$ \\
\hline & 3 & My interaction with the web-based tool is clear and understandable $(0.8187)$ \\
\hline & 4 & I find the web-based tool easy to use $(0.8006)$ \\
\hline & 5 & $\begin{array}{l}\text { Interacting with the web-based tool will not require a lot of } \\
\text { my mental effort }(0.8169)\end{array}$ \\
\hline & 6 & It is easy to remember how to perform tasks using the web-based tool $(0.7256)$ \\
\hline \multirow[t]{6}{*}{ Usefulness $(0.9501)$} & 1 & Using the web-based tool would improve my performance in this course $(0.8423)$ \\
\hline & 2 & Using the web-based tool would increase my productivity in this course $(0.8807)$ \\
\hline & 3 & Using the web-based tool would enhance my effectiveness in this course $(0.8864)$ \\
\hline & 4 & I find the web-based tool would be useful in this course $(0.8662)$ \\
\hline & 5 & $\begin{array}{l}\text { Using web-based tool in my job would enable me to accomplish } \\
\text { tasks more quickly }(0.8318)\end{array}$ \\
\hline & 6 & Using web-based tool would make it easier to do my job (0.7704) \\
\hline \multirow[t]{2}{*}{ Use intention $(0.9180)$} & 1 & I intend to review some concepts using the web-based tool frequently $(0.8485)$ \\
\hline & 2 & $\begin{array}{l}\text { I intend to compare some theoretical and practical concepts explained } \\
\text { in classes with the point of view of the web-based tool }(0.8485)\end{array}$ \\
\hline \multirow[t]{2}{*}{ Use (0.8403) } & 1 & $\begin{array}{l}\text { How many times per week have you used the } \\
\text { web-based tool? (Average value) }(0.7247)\end{array}$ \\
\hline & 2 & $\begin{array}{l}\text { How many hours per week have you used the web-based } \\
\text { tool? (Average value) }(0.7247 \text { ) }\end{array}$ \\
\hline
\end{tabular}

2000), and easy of use, usefulness, behavioural intention and use (Davis \& Venkatesh, 2004; Hubona \& Geitz, 1997; Laitenberger \& Dreyer, 1998). The last four dimensions represent the TAM model as it was originally proposed by Davis (Lee, Kozar, \& Larsen, 2003), and the previous ones are the external variables that may have some influence in this model.

First of all, the reliability of the questionnaire must be proven, which means that a set of questions that will always elicit consistent and reliable responses, even if they were replaced with other similar questions, is used. A dimension generated from such a set of questions that return a stable 
response is said to be reliable. Cronbach's alpha is a reliability index associated with the variation accounted for by the true score of the "underlying construct". A construct is the hypothetical variable or dimension that is being measured. Cronbach's alpha measures how well a set of items (or variables) measures a single one-dimensional latent construct. The formula for the standardized Cronbach's alpha is as follows.

$$
\alpha=\frac{N \cdot \bar{r}}{1+(N-1) \cdot \bar{r}}
$$

where $N$ is equal to the number of items and $\bar{r}$ is the average inter-item correlation among the items. In Table 2, the value of $\alpha$ (under the dimension between brackets) and the inter-item correlation associated to each question have been calculated. $\alpha$ Coefficient ranges in value from 0 to 1 . The higher the score, the more reliable the generated scale is. A value above 0.7 may be an acceptable reliability coefficient although lower thresholds are sometimes used in the literature. The validated questionnaire of Table 2 clearly achieves this condition for each dimension.

\section{Validation of the structural and measurement model}

As there are a lot of items in the questionnaire, it is necessary to reduce its number. Principal components analysis (PCA) is a quantitatively rigorous method for achieving this simplification. It generates a new set of variables, called principal components. Each principal component is a linear combination of the original variables. All the principal components are orthogonal to each other so there is no redundant information. The principal components as a whole form an orthogonal basis for the space of the data. Table 3 shows the results obtained from this analysis: the first column is the corresponding dimension, next, the number of principal components, and, finally, the variances explained by these components.

The number of items has been reduced from 57 to 12, taking into account the minimum number of components that can explain al least a $70 \%$ of the variance of each dimension, as it is shown in Table 3.

Table 3

Reduction of items using principal components analysis

\begin{tabular}{lll}
\hline Dimension & Components & Explained variance \\
\hline Learning goal orientation (LGO) & 3 & 0.7417 \\
Application specific self-efficacy (ASSE) & 4 & 0.7016 \\
Enjoyment (E) & 1 & 0.7579 \\
Focused immersion (FI) & 2 & 0.8766 \\
Curiosity (C) & 1 & 0.6943 \\
Playfulness (P) & 1 & 0.8624 \\
Voluntariness (V) & 1 & 0.7341 \\
Easy of use (EOU) & 1 & 0.6930 \\
Usefulness (U) & 1 & 0.8024 \\
Use intention (UI) & 1 & 0.9245 \\
Use (Us) & 1 & 0.8726 \\
\hline
\end{tabular}


Using the data in the new coordinate system, defined by the principal components of each dimension, the correlations among these dimensions can be evaluated, as it is illustrated in Table 4. The higher values in this table illustrate the main relationship among dimensions. Analyzing the last row of the correlation matrix, it can be seen that several of them have a direct impact in the use of the system; use intention (0.4463), usefulness (0.2931), easy of use (0.3095), playfulness (0.2750), curiosity (0.3545), enjoyment (0.3210) and application specific self-efficacy (0.3938).

But, moreover some dimensions may have an indirect impact in the use of the system through intermediate dimensions, and they have to be taken into account. In Table 4, direct relationships among dimensions have been remarked with the corresponding cells in bold, while indirect relationships are shown with the corresponding cells in italicized. From these values, the hypotheses to be contrasted in this study can be established:

- Enjoyment has a positive incidence over playfulness, curiosity and easy of use.

- Application specific self-efficacy has a positive incidence over playfulness, curiosity and easy of use.

- Playfulness has a positive incidence over curiosity.

- Curiosity has a positive incidence over usefulness.

The rest of the hypotheses to be contrasted are the typical relationship among the major variables of TAM: easy of use, usefulness, use intention and use.

Among the external variables, it is worth mentioning the four highly correlated dimensions:

- Application specific self-efficacy. It is defined as the individual perception of efficacy in using a specific application or system within the domain of general computing. Questions associated to this dimension try to measure the belief that one has the capability of performing a particular task.

- Curiosity, tapping into the extent the experience arouses an individual's sensory and cognitive curiosity.

Table 4

Correlations among the detected dimensions related to the use of the tool

\begin{tabular}{lrrrrrrrrrrr}
\hline & LGO & ASSE & \multicolumn{1}{l}{ E } & \multicolumn{1}{l}{ FI } & \multicolumn{1}{l}{ C } & \multicolumn{1}{l}{ P } & V & EOU & U & UI & Us \\
\hline LGO & 1 & 0.134 & 0.308 & -0.271 & 0.339 & 0.348 & 0.147 & -0.007 & -0.064 & -0.020 & 0.160 \\
ASSE & 0.134 & 1 & 0.339 & -0.352 & 0.425 & 0.306 & 0.152 & 0.629 & 0.360 & 0.300 & 0.394 \\
E & 0.308 & 0.339 & 1 & -0.491 & 0.531 & 0.535 & -0.008 & 0.378 & 0.401 & 0.288 & 0.321 \\
FI & -0.271 & -0.352 & -0.491 & 1 & -0.622 & -0.542 & 0.013 & -0.319 & -0.295 & -0.313 & -0.369 \\
C & 0.339 & $\mathbf{0 . 4 2 5}$ & $\mathbf{0 . 5 3 1}$ & -0.622 & 1 & 0.752 & 0.017 & 0.413 & 0.441 & 0.328 & 0.355 \\
P & 0.348 & $\mathbf{0 . 3 0 6}$ & $\mathbf{0 . 5 3 5}$ & -0.542 & $\mathbf{0 . 7 5 2}$ & 1 & 0.117 & 0.359 & 0.393 & 0.231 & 0.275 \\
V & 0.147 & 0.152 & -0.008 & 0.013 & 0.017 & 0.117 & 1 & 0.295 & 0.024 & -0.068 & -0.017 \\
EOU & -0.007 & $\mathbf{0 . 6 2 9}$ & $\mathbf{0 . 3 7 8}$ & -0.319 & 0.413 & 0.359 & 0.295 & 1 & 0.487 & 0.369 & 0.310 \\
U & -0.064 & 0.360 & 0.401 & -0.295 & $\mathbf{0 . 4 4 1}$ & 0.393 & 0.024 & $\mathbf{0 . 4 8 7}$ & 1 & 0.549 & 0.293 \\
UI & -0.020 & 0.300 & 0.288 & -0.313 & 0.328 & 0.231 & -0.068 & $\mathbf{0 . 3 6 9}$ & $\mathbf{0 . 5 4 9}$ & 1 & 0.446 \\
Us & 0.160 & 0.394 & 0.321 & -0.369 & 0.355 & 0.275 & -0.017 & 0.310 & 0.293 & $\mathbf{0 . 4 4 6}$ & 1 \\
\hline
\end{tabular}


- Enjoyment refers to the extent to which the activity of using a computer system is perceived to be personally enjoyable in its own right aside from the instrumental value of the technology. - Playfulness is related to a personal attitude when using the tool and it is defines as the degree of cognitive spontaneity in computer interactions.

The results of the study clearly point out the important roles of application specific selfefficacy, curiosity, enjoyment and playfulness in positively influencing the decision of using a web-based technology and, subsequently, its final use. Notice that these results inform about the weakness of the tool. In this case, it has been detected that interactive contents and cooperative learning will improve enjoyments and curiosity of students when using the tool. In this way, a future version of the web-site is going to be developed taking into account these results.

Respect to the actual use of the tool, the results obtained showed these two important ratios:

- Rate of students who have used the web tool: $114 / 142=80.28 \%$.

- Average use of the contents of the web tool (114 students): $43.8 \%$.

This means that a little more than $80 \%$ of the students have used, at least once, the web tool. Apart from the items sown in Table 2, the questionnaire also contained dichotomous questions (that is, questions with two possible answers) about the use of different contents of the tool. The obtained results suggest that students have navigated through the $44 \%$ of the contents of the web-based tool, and that the more visited contents of the tool are related to interactivity (databases) and practical applications (DSK30 based content). This result is in accordance with the most important external variables detected, such us enjoyment, playfulness and curiosity.

To validate the hypothesis previously described, the partial least squares (PLS) technique is used (Chin, 1998). Partial least squares regression is an extension of the multiple linear regression models. In its simplest form, a linear model specifies the (linear) relationship between a dependent variable (the use of the tool), and a set of predictor variables (external variables obtained in the previous section). The objective in PLS is to maximize the explanation variance. Thus, $R^{2}$ and the significance of relationships among dimensions or constructs are measures indicative of how well a model is performing. The conceptual core of PLS is an iterative combination of principal component analysis relating measures to constructs, and path analysis permitting the construction of a system of constructs. The hypothesizing of relationships between measures and constructs, and constructs and other constructs is guided by the results of the applications of PCA in the previous section. The estimation of the parameters representing the measurement and path relationships is accomplished using ordinary least squares (OLS) techniques.

One of the key benefits of using PLS as a structural modeling technique is that it may work with smaller samples. In this study, the sample size of 142 is high enough for PLS. Fig. 11 (obtained using PLS Graph, 3.0, (Chin, 2003)) shows the result of PLS technique. The right side of this figure is formed by the typical constructs of TAM, while external variables of the model are placed on the left side. Several combinations were examined using different relative positions for the external variables constructs, according to the correlations of Table 4 . 


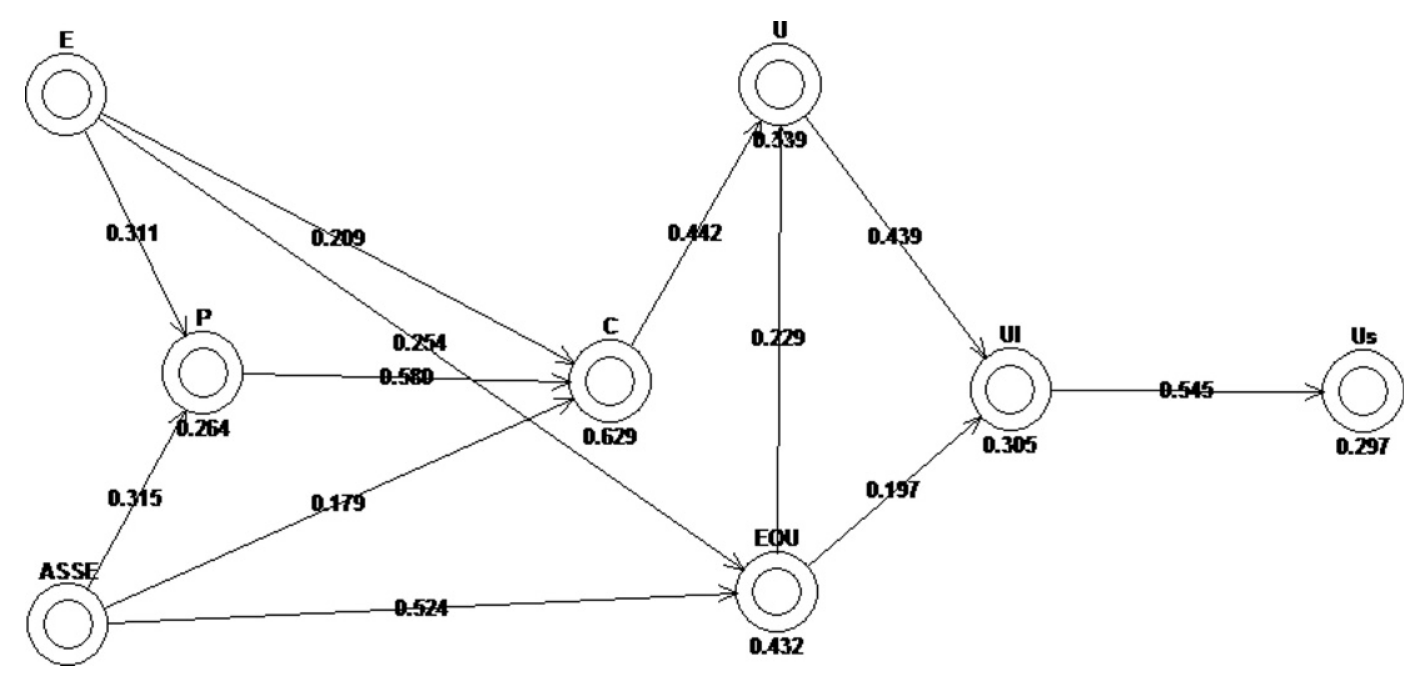

Fig. 11. PLS result: TAM.

The $R^{2}$ values (showed in Fig. 11 under the corresponding construct) represent the predictive power within those constructs as explained by the measures that represent the preceding constructs. The path loadings represent the causal links from one construct to the other. According to Fig. 11, a $30 \%$ of the variance of the use of the tool is able to be explained, which is an acceptable value for this kind of analysis. The number of indicators chosen for each constructs is detailed in Table 5. The criterion for this election is also based in PCA results of the previous section. The principal component of each dimension or construct has been examined and the indicators with the highest weight in this principal component have been chosen. This election guarantees that the indicators represent the highest variance of the construct they are measuring, while, at the same time, the number of indicators for PLS analysis is reduced. A rule of thumb is to accept items with loadings of 0.7 or more, which implies more shared variance between the construct and its measures than error variance. The results of Table 5 show that all of the indicators loaded at 0.7 or greater on their corresponding constructs. Internal consistency was tested using composite reliability, and the results are shown in the same table. All of them were over the 0.7 threshold. Discriminant validity was tested using the correlation matrix of constructs. This correlation matrix is illustrated on the right side of Table 5. Its diagonal has been replaced, for comparison purposes, by the square root of the average variance extracted (Fornell \& Larcker, 1981). For adequate discriminant validity, the diagonal elements should be significantly greater than the off-diagonal elements in the corresponding rows and columns, as was the case for the selected model (Fornell, 1982).

To asses the statistical significance of the path coefficients, which are standardized betas, a bootstap analysis was performed. The use of bootstrapping, as opposed to traditional $t$-tests, allows the testing of the significance of parameter estimates from data which are not assumed to be multivariate normal. In this case, 489 sub samples were created by removing 11 cases from the total data set. PLS estimates the parameters of each sub sample and "pseudo values" are calculated by applying the bootstrap formula. Table 6 shows that all the paths proved to be significant at the $p$-value $<0.01$ level. 
Table 5

PLS results

\begin{tabular}{|c|c|c|c|c|c|c|c|c|c|c|c|}
\hline & \multirow[t]{2}{*}{ Indicator } & \multirow[t]{2}{*}{ Load } & \multirow[t]{2}{*}{ Consistency } & \multicolumn{8}{|c|}{ Discriminant validity } \\
\hline & & & & ASSE & $\mathrm{E}$ & $\mathrm{C}$ & $\mathrm{P}$ & $\mathrm{EOU}$ & $\mathrm{U}$ & UI & Us \\
\hline \multirow[t]{5}{*}{ ASSE } & ASSE6 & 0.7465 & 0.894 & 0.793 & 0.351 & 0.500 & 0.425 & 0.614 & 0.482 & 0.476 & 0.483 \\
\hline & ASSE7 & 0.8248 & & & & & & & & & \\
\hline & ASSE8 & 0.8126 & & & & & & & & & \\
\hline & ASSE9 & 0.7841 & & & & & & & & & \\
\hline & ASSE10 & 0.7923 & & & & & & & & & \\
\hline \multirow[t]{3}{*}{$\mathrm{E}$} & E1 & 0.8884 & 0.907 & 0.351 & 0.875 & 0.516 & 0.421 & 0.432 & 0.490 & 0.463 & 0.397 \\
\hline & E2 & 0.8752 & & & & & & & & & \\
\hline & E3 & 0.8606 & & & & & & & & & \\
\hline \multirow[t]{3}{*}{$\mathrm{C}$} & $\mathrm{C} 1$ & 0.7757 & 0.875 & 0.500 & 0.516 & 0.837 & 0.744 & 0.441 & 0.539 & 0.461 & 0.396 \\
\hline & $\mathrm{C} 2$ & 0.9146 & & & & & & & & & \\
\hline & $\mathrm{C} 3$ & 0.8135 & & & & & & & & & \\
\hline \multirow[t]{3}{*}{$\mathrm{P}$} & $\mathrm{P} 1$ & 0.9473 & 0.965 & 0.425 & 0.421 & 0.744 & 0.949 & 0.347 & 0.406 & 0.289 & 0.295 \\
\hline & $\mathrm{P} 2$ & 0.9622 & & & & & & & & & \\
\hline & P3 & 0.9381 & & & & & & & & & \\
\hline \multirow[t]{6}{*}{ EOU } & EOU1 & 0.7545 & 0.930 & 0.614 & 0.432 & 0.441 & 0.347 & 0.830 & 0.429 & 0.386 & 0.387 \\
\hline & EOU2 & 0.8399 & & & & & & & & & \\
\hline & EOU3 & 0.8928 & & & & & & & & & \\
\hline & EOU4 & 0.8502 & & & & & & & & & \\
\hline & EOU5 & 0.8607 & & & & & & & & & \\
\hline & EOU6 & 0.7704 & & & & & & & & & \\
\hline \multirow[t]{6}{*}{$\mathrm{U}$} & U1 & 0.8571 & 0.956 & 0.482 & 0.490 & 0.539 & 0.406 & 0.429 & 0.885 & 0.524 & 0.384 \\
\hline & U2 & 0.8949 & & & & & & & & & \\
\hline & U3 & 0.8970 & & & & & & & & & \\
\hline & U4 & 0.9111 & & & & & & & & & \\
\hline & U5 & 0.8853 & & & & & & & & & \\
\hline & U6 & 0.8662 & & & & & & & & & \\
\hline \multirow[t]{2}{*}{ UI } & UI1 & 0.9538 & 0.953 & 0.476 & 0.463 & 0.461 & 0.289 & 0.386 & 0.524 & 0.954 & 0.547 \\
\hline & UI2 & 0.9534 & & & & & & & & & \\
\hline \multirow[t]{2}{*}{ Us } & Us1 & 0.9210 & 0.926 & 0.483 & 0.397 & 0.396 & 0.295 & 0.387 & 0.384 & 0.547 & 0.928 \\
\hline & Us2 & 0.9358 & & & & & & & & & \\
\hline
\end{tabular}

Table 6

Path coefficients table ( $T$-statistic)

\begin{tabular}{lllllllll}
\hline & Us & UI & U & EOU & ASSE & E & C & P \\
\hline Us & 0.000 & 9.250 & 0.000 & 0.000 & 0.000 & 0.000 & 0.000 & 0.000 \\
UI & 0.000 & 0.000 & 5.292 & 2.592 & 0.000 & 0.000 & 0.000 & 0.000 \\
U & 0.000 & 0.000 & 0.000 & 3.127 & 0.000 & 0.000 & 6.474 & 0.000 \\
EOU & 0.000 & 0.000 & 0.000 & 0.000 & 6.165 & 3.204 & 0.000 & 0.000 \\
ASSE & 0.000 & 0.000 & 0.000 & 0.000 & 0.000 & 0.000 & 0.000 & 0.000 \\
E & 0.000 & 0.000 & 0.000 & 0.000 & 0.000 & 0.000 & 0.000 & 0.000 \\
C & 0.000 & 0.000 & 0.000 & 0.000 & 2.917 & 2.804 & 0.000 & 8.916 \\
P & 0.000 & 0.000 & 0.000 & 0.000 & 3.904 & 3.429 & 0.000 & 0.000 \\
\hline
\end{tabular}




\section{Conclusion}

A web-based educational tool, designed with Shockwave ${ }^{\text {TM }}$ and Macromedia Director ${ }^{\text {TM }}$ has been presented as a teaching methodology in an undergraduate course involved with advanced microprocessors architectures and their applications. The tool has been designed taking into account the major variables of the TAM model. In order to measure its use and to improve the educational tool, a questionnaire has been developed and validated with the Cronbach's alpha estimator of reliability. Then, principal component analysis is incorporated as a priori theoretical and measurement model to obtain the hypotheses and the indicators to measure each of the identified constructs or dimensions. Finally, PLS technique has been applied to analyze the measurement model and structural model concurrently in order to validate the previous set of hypotheses and indicators. Two types of conclusions have been obtained. First, the final use of the tool; more than $80 \%$ of the students have navigated through the $44 \%$ of the tool contents. Second, the external variables with a significant influence in this use: application specific self-efficacy (easy navigation through the web-site is guarantied due to the connection between classroom and web-site contents), enjoyment, playfulness and curiosity. These variables can be improved promoting interactivity and cooperative learning.

Notice that the proposed study could be extended to any web-based educational tool, because the measurement of the acceptance and the identification of the external variables is the only way of knowing if an educational tool is properly working in a specific teaching methodology, playing the role it was designed for.

\section{References}

Abdel-Qader, I. M., Bazuin, B. J., Mousavinezhad, H. S., \& Patrick, J. K. (2003). Real-time digital signal processing in the undergraduate curriculum. IEEE Transactions on Education, 46(1), 95-101.

Aedo, P., Díaz, P., Fernández, C., Martín, G. M., \& Berlanga, A. (2000). Assessing the utility of an interactive electronic book for learning the Pascal language. IEEE Transactions on Education, 43(3), 403-413.

Agarwal, R., \& Karahanna, E. (2000). Time flies when you're having fun cognitive absorption and beliefs about information technology usage. MIS Quarterly, 24(4), 665-694.

Almeida, S. F., Piazzalunga, R., Ribeiro, V. G., Casemiro, M. B., \& Moreno, R. (2003). Combining interactivity and improved layout while creating educational software for the Web. Computers \& Education, 40, $271-284$.

Avouris, N. M., Tselios, N., \& Tatakis, E. C. (2001). Development and evaluation of a computer-based laboratory teaching tool. Computer Applications in Engineering Education, 9(1), 8-19.

Bagui, S. (1998). Reasons for increased learning using multimedia. Journal of Educational Multimedia and Hypermedia, 7, 3-18.

Cappel, J. J., \& Hayen, R. L. (2004). Evaluating e-learning: a case study. Journal of Computer Information Systems, 44(4), 49-56.

Carley, L., Khosla, P., \& Unetich, R. (2000). Teaching 'Introduction to Electrical and Computer Engineering' in context. Proceedings of the IEEE, 88, 8-22.

Chevalier, L. R., Craddock, J. N., Riley, P. C., \& Trunk, B. J. (2000). Interactive multimedia labware for strength of materials laboratory. Computer Applications in Engineering Education, 8(1), 31-37.

Chin, W. W. (1998). The partial least squares approach for structural equation modelling. In G. A. Marcoulides (Ed.), Modern methods for business research (pp. 295-336). Mahwah, NJ: Erlbaum.

Chin, W. W. (2003). PLS-Graph (Version 3.00, Build 1058) [Computer software]. University of Houston.

Christian, W., \& Belloni, M. (2001). Physlets: Teaching physics with interactive curricular material. Englewood Cliffs, NJ: Prentice-Hall. 
Communiqué of the Conference of Ministers responsible for Higher Education (2003). Realising the European Higher Education Area. Berlin.

Conole, G., Dyke, M., Oliver, M., \& Seale, J. (2004). Mapping pedagogy and tools for effective learning design. Computers \& Education, 43, 17-33.

Davis, F. D., \& Venkatesh, V. (2004). Toward preprototype user acceptance testing of new information systems: implications for software project management. IEEE Transactions on Engineering Management, 51(1), $31-46$.

Felder, R. M., Felder, G. N., \& Dietz, J. (1998). A longitudinal study of engineering students performance and retention V. Comparisons with traditionally-taught students. Journal of Engineering Education, 98(4), 469-480.

Fornell, C., \& Larcker, D. F. (1981). Structural equation models with unobservable variables and measurement errors. Journal of Marketing Research, 18(1), 39-50.

Fornell, C. (1982). A second generation of multivariate analysis, methods: Volume 1. New York, NY: Praeger Publishers.

Fuller, D. A., \& Moreno, A. F. (2004). Experimenting with a computer-mediated collaborative interaction model to support engineering courses. Computer Applications in Engineering Education, 12(3), 175-188.

Hubona, G. S., \& Geitz, S. (1997). External variables, beliefs, attitudes and information technology usage behavior. Proceedings of the thirtieth Hawaii international conference on system sciences, 3, 21-28.

Hurley, W. G., \& Lee, C. K. (2005). Development, implementation, and assessment of a web-based power electronics laboratory. IEEE Transactions on Education, 48(4), 567-573.

Joint declaration of the European Ministers of Education (1999). The European Higher Education Area. Bologna.

Laitenberger, O., \& Dreyer, H.M. (1998). Evaluating the usefulness and the easy of use of a web-based inspection data collection tool. In Proceedings 5th international software metrics symposium (pp. 122-132).

Lee, Y., Kozar, K. A., \& Larsen, K. R. T. (2003). The technology acceptance model: past, present, and future. Communications of the Association for Information Systems, 12, 752-780.

Metzger, M. J., Flanagina, A. J., \& Zwarun, L. (2003). College student web use, perceptions of information credibility, and verification behaviour. Computers \& Education, 41, 271-290.

Milliken, J., \& Barnes, L. P. (2002). Teaching and technology in higher education: student perceptions and personal reflections. Computers \& Education, 39, 223-235.

Ngai, E. W. T., Poon, J. K. L., \& Chan, Y. H. C. (2007). Empirical examination of the adoption of WebCT using TAM. Computers \& Education, 48(2), 250-267.

Ong, Chorng-Shyong, Lai, Jung-Yu, \& Wang, Yi-Shun (2004). Factors affecting engineers' acceptance of asynchronous e-learning systems in high-tech companies. Information and Management, 41(6), 795-804.

Pahl, C. (2003). Managing evolution and change in web-based teaching and learning environments. Computers \& Education, 40, 99-114.

Roppel, T. (2000). An interdisciplinary laboratory sequence in electrical and computer engineering: curriculum design and assessment results. IEEE Transaction on Education, 43, 143-152.

Selim, H. M. (2003). An empirical investigation of student acceptance of course websites. Computers \& Education, 40, 343-360.

Taylor, R. L., Heer, D., \& Fiez, T. S. (2003). Using an integrated platform for learning to reinvent engineering education. IEEE Transaction on Education, 46(4), 409-419.

Toral, S. L., Barrero, F., Martínez-Torres, M. R., Gallardo, S., \& Lillo, J. (2005). Implementation of a web-based educational tool for digital signal processing teaching using the technological acceptance model. IEEE Transactions on Education, 48(4), 632-641.

Wilson, J., \& Jennings, W. (2000). Studio courses: How information technology is changing the way we teach, on campus and off. Proceedings of the IEEE, 88, 72-80.

Yi, M. Y., \& Hwang, Y. (2003). Predicting the use of web-based information systems: self-efficacy, enjoyment, learning goal orientation, and the technology acceptance model. International Journal of Human-Computer Studies, 59, 431-449.

Sergio L. Toral Marín was born in Rabat, Morocco, in 1972. He received the electrical engineering and Ph.D. degrees at University of Seville in 1995 and 1999, respectively. He is currently a full Professor at the Electronic Engineering Department of the University of Seville. His research interests include microprocessor and DSP devices systems, e-learning tools and their evaluation, stochastic processing and their industrial applications. 
Federico J. Barrero García was born in Seville, Spain, in 1967. He received the electrical engineering and Ph.D. degrees at University of Seville in 1992 and 1998, respectively. In 1992 he joined the Electronic Engineering Department at the University of Seville, where he presently maintains a full Professor position. His current interests include microprocessor and DSP devices systems, e-learning and multimedia educational tools, fuzzy logic-based system, and control of Electrical Drives and Power Electronic.

Rocío Martínez Torres was born in Madrid, Spain, in 1973. She received the degree in Business Administration in 1996 and the Ph. D. degree from the University of Seville, Spain, in 2003. She is currently a full Professor at Business Administration and Marketing Department of the University of Seville. Her research interests include intellectual capital and knowledge management, and acceptance of e-learning tools. 